\title{
Pharmacotherapeutic management of chronic noncancer pain in primary care: lessons for pharmacists
}

This article was published in the following Dove Press journal:

Journal of Pain Research

24 March 2014

Number of times this article has been viewed

\author{
Ghaya Jouini ${ }^{1-3}$ \\ Manon Choinière ${ }^{3,4}$ \\ Elisabeth Martin 2,3 \\ Sylvie Perreault ${ }^{1,5}$ \\ Djamal Berbiche ${ }^{2,3}$ \\ David Lussier ${ }^{6-8}$ \\ Eveline Hudon ${ }^{2,3,9}$ \\ Lyne Lalonde ${ }^{1-3,10}$
}

'Faculty of Pharmacy, Université de Montréal, Montreal, Quebec, Canada; 2Équipe de recherche en soins de première ligne, Centre de santé et de services sociaux de Laval, Laval, Quebec, Canada; ${ }^{3}$ Centre de recherche du Centre hospitalier de l'Université de Montréal (CRCHUM), Montreal, Quebec, Canada; ${ }^{4}$ Department of Anesthesiology, Faculty of Medicine, Université de Montréal, Montreal, Quebec, Canada; ${ }^{5}$ Sanofi-Aventis Endowment Research Chair in Optimal Drug Use, Université de Montréal, Montreal, Quebec, Canada; 'Institut universitaire de gériatrie de Montréal, Montreal, Quebec, Canada; ${ }^{7}$ Division of Geriatric Medicine and AlanEdwards Center for Research on Pain, McGill University, Montreal, Quebec, Canada; ${ }^{8}$ Department of Medicine, Faculty of Medicine, Université de Montréal, Montreal, Quebec, Canada; ' Department of Family Medicine and Emergency, Faculty of Medicine, Université de Montréal, Montreal, Quebec, Canada; ${ }^{10}$ Sanofi-Aventis Endowment Research Chair in Ambulatory Pharmaceutical Care, Université de Montréal and Centre de santé et de services sociaux de Laval, Quebec, Canada

Correspondence: Lyne Lalonde Centre de recherche du Centre hospitalier de l'Université de Montréal, 850 Saint-Denis Street, Tour SaintAntoine, Room S03.436, Montreal, Quebec, H2X 0A9, Canada

$\mathrm{Tel}+$ I 5 I48908000 ext I549|

Fax +I 5144127038

Email lyne.lalonde@umontreal.ca
Purpose: Describe the pharmacotherapeutic management of primary-care patients with chronic noncancer pain, assess their satisfaction with pain treatment, and identify the determinants of their satisfaction.

Methods: A cohort study was conducted in Quebec (Canada). Patients reporting chronic noncancer pain with an average pain intensity of at least 4 on a $0-10$ scale $(10=$ worst possible pain) and having an active analgesic prescription from a primary-care physician were recruited. They completed a telephone interview and a self-administered questionnaire to document their pain, emotional well-being, satisfaction with treatment, and barriers/beliefs/attitudes about pain and its treatment. Information on pharmacotherapy was based on an administrative provincial database and pharmacies' charts. Determinants of patients' satisfaction were identified using multivariate linear regression models.

Results: Four hundred and eighty six patients participated. Their mean age was 58.4 years and they had had pain for a mean of 11.7 years (standard deviation, \pm 11.1 ) at an average pain intensity of 6.5 in the past week. Although $90 \%$ reported adverse gastrointestinal effects, $36.4 \%$ and $54.4 \%$ of these patients took no over-the-counter or prescribed medication for constipation or nausea, respectively. On a scale from 0-100, the mean overall satisfaction score was 64.7 (95\% confidence interval $[\mathrm{CI}]=63.5-65.9)$. Patient satisfaction was low, particularly regarding the "information about pain and its treatment" (mean 50.6; 95\% CI =47.6-53.7) and "treatment efficacy" (mean 53.6; 95\% CI =51.5-55.6) subscales. The overall treatment satisfaction score decreased with more pain disability, probable depression and anxiety, more barriers to pain treatment, higher incidence of nausea, and use of over-the-counter analgesics.

Conclusion: In primary care, patients' level of satisfaction with their pain treatment is not optimal. This study underlines how the expanded scope of practice of community pharmacists may allow them to play a pivotal role in providing information, discussing barriers to pain treatment, and monitoring pain disability, and by appropriately managing pharmacotherapy to optimize effectiveness while minimizing adverse effects.

Keywords: noncancer chronic pain, primary care, pharmacotherapy, analgesic, adverse effects, cohort study

\section{Introduction}

Chronic noncancer pain (CNCP) has been reported by one in five Canadians, ${ }^{1,2}$ with similar prevalence around the world. ${ }^{3,4} \mathrm{CNCP}$ is a source of personal suffering and constitutes a major economic burden for our society. ${ }^{2,5-7}$ Like other chronic diseases, chronic pain is managed essentially in primary care, where it accounts for about $20 \%$ of all patients seen. ${ }^{5,8}$ In a US nationwide telephone survey, only $5 \%$ of these patients reported having ever consulted a pain specialist. ${ }^{9} \mathrm{CNCP}$ is often poorly managed. ${ }^{1,10}$

submit your manuscript | www.dovepress.com 
An American Pain Society survey revealed that more than $40 \%$ of patients with chronic pain suffered from uncontrolled pain. ${ }^{10}$ Pharmacotherapy is an important component of pain treatment. Pain-relievers top the list of classes of therapeutic drugs prescribed during visits to physicians' offices and emergency rooms. ${ }^{11}$

Patient satisfaction is important in the evaluation of CNCP management and, as in other diseases, is associated with treatment effectiveness. ${ }^{12,13}$ Traditionally, successful pain management was defined as the achievement of analgesia without excessive adverse drug reactions; adverse effects often lead patients to discontinue their therapy ${ }^{14,15}$ and to express their dissatisfaction with pain treatment., ${ }^{3,16}$ However, other studies ${ }^{17,18}$ have reported high satisfaction ratings despite significant pain levels (the "pain paradox"). ${ }^{17}$ Psychosocial functioning and medical care management also influence patient satisfaction. ${ }^{19-21}$ Our understanding of the factors influencing patient satisfaction is restricted by the fact that, to our knowledge, only two studies ${ }^{22,23}$ have drawn a comprehensive picture of the pharmacotherapeutic management of CNCP in primary care, including biopsychosocial and medical care characteristics.

We constituted a large cohort of primary-care patients from Quebec (Canada) suffering from CNCP. We used the data from this cohort to: 1) describe the pharmacotherapeutic pain management of these cohort patients; 2) assess their satisfaction with pain treatment; and 3) identify the determinants of their satisfaction. Community pharmacists may play a pivotal role in the management of pain therapy: they are highly accessible and well trained, and recent legislative changes in Quebec and Canada allow them to expand their scope of practice. Our results will therefore be discussed from a community pharmacy point of view.

\section{Methods Study design}

As part of the ACCORD Program (Application Concertée des Connaissances et Ressources en Douleur), a knowledge translation research program in the field of $\mathrm{CNCP}$, a cohort study was conducted. ${ }^{24}$ Patients with $\mathrm{CNCP}$ having an active analgesic prescription from a primary-care physician were recruited in community pharmacies randomly selected in Quebec. Patients completed a telephone interview and a selfadministered questionnaire. Prescribed medications delivered during the year preceding recruitment were documented using the administrative database of the Régie de l'assurance maladie du Québec (RAMQ) or the pharmacies' charts. Ethics approval was obtained from the Comité scientifique et d'éthique de la recherche of the Centre de santé et de services sociaux de Laval. Patients signed an informed consent form. Pharmacists received CAD $\$ 50$ for each consenting patient, and patients received $\$ 25$ if they completed the questionnaire.

\section{Study population}

The study was conducted on the territory of the Réseau universitaire intégré de santé of the Université de Montréal, which comprises six regions accounting for $40 \%$ of Quebec's population: Mauricie et Centre du Québec; Laval; Montréal; Laurentides; Lanaudière; and Montérégie. Using the Quebec Health Ministry's Atlas, we identified 513 community pharmacies. A random sampling stratified by region and weighted by the number of pharmacies within each region was performed to recruit a total of 60 pharmacies. Each participating pharmacy was asked to identify between 10 and 15 consecutive potentially eligible patients. To compensate for pharmacies that did not recruit the expected number of patients, additional pharmacies were invited to participate during the course of the study.

Patients were deemed eligible if they fulfilled the following criteria: 1 ) aged at least 18 years; 2) suffering from CNCP, defined as pain lasting for 6 months or more and not related to cancer; 3 ) reporting an average pain intensity in the past 7 days of at least 4 on a $0-10$ intensity scale where 0 means "no pain" and 10 means "worst possible pain"; 4) suffering from pain at least 2 days a week; 5) able to speak and read French or English; and 6) having an active prescription from a primary-care physician for at least one of the following classes of analgesics: acetaminophen, nonsteroidal anti-inflammatory drugs, anticonvulsants, antidepressants, muscle relaxants, and opioids. We did not include patients treated solely with over-the-counter (OTC) analgesics (eg, acetaminophen). However, considering that when these medications are prescribed by a physician they are reimbursed by public or private drug insurance programs, we may have excluded only a small proportion of the target population. Patients who had migraine as the sole cause of pain were excluded, as were patients with any health problem that might prevent them from providing informed consent.

\section{Procedure and measurement tools}

\section{Pain characteristics}

In the telephone interview, patients rated their average and worst pain intensity over the past 7 days, and their current pain intensity using a $0-10$ numerical intensity-scale, where 0 means "no pain" and 10 "worst possible pain." They reported time since initial onset of pain and frequency of 
pain in the past week ("always", "occasionally", "never"). To document sites and causes of pain, patients were asked: "Where do you usually have pain?" and "I will read a list of diagnoses that can be at the cause of your pain. Please, stop me each time I name a diagnosis corresponding to your condition."

\section{Psychosocial characteristics}

Impact of pain on daily functioning was assessed in the telephone interview using the ten interference items of the modified Brief Pain Inventory (BPI). The BPI is a widely used instrument in pain research and its psychometric qualities are well documented. ${ }^{25,26}$ For each item, patients were asked to rate on a $0-10$ intensity scale $(0=$ does not interfere, $10=$ interferes completely) the extent to which pain interferes with their general activity, walking ability, mood, normal work, relations with other people, sleep, enjoyment of life, self-care, recreational activities, and social activities. A global BPI score is the average rating on the ten items. ${ }^{25}$

Impact of pain on sleep was documented with the Chronic Pain Sleep Inventory ${ }^{27}$ during the telephone interview. A sleep problems index score is the mean of items 1,3 , and $4 .{ }^{27}$ Scores range from $0-10$. The higher the score, the worse the quality of sleep. Internal consistency reliability of the single sleep problems index is good $(>0.90) .{ }^{27} \mathrm{We}$ translated the original English version into French using a forward-backward procedure.

The Hospital Anxiety and Depression Scale ${ }^{28}$ was included in the self-administered questionnaire. Scores ranged from $0-21$. Depression and anxiety were rated as "absent" ( $\leq 7)$, "uncertain" (8-10), or "probable" $(\geq 11) .{ }^{28}$ This scale was validated for primary-care patients ${ }^{29}$ and patients with chronic pain. ${ }^{30}$

The Barriers Questionnaire II, ${ }^{31}$ included in the selfadministered questionnaire, comprises 27 items grouped into four subscales (physiological effects, fatalism, communication, harmful effects). Mean scores for the total scale and subscales were computed. A higher score suggests a greater barrier to pain treatment. The questionnaire has high internal consistency (reliability coefficients ranging from 0.86-0.89). ${ }^{31}$ Because it was designed for patients suffering from cancer pain, some of the items were adapted for this study. It was translated to French using a forward-backward procedure.

\section{Analgesics use}

Analgesics use in the year preceding recruitment was documented for each patient using either the RAMQ database or the pharmacies' charts. Using pharmacies' charts was important to obtain information on patients not insured by the RAMQ for their prescription drugs. Antidepressants and anticonvulsants considered were those recommended for pain treatment ${ }^{32,33}$ and were documented only for patients not reporting epilepsy or depression, respectively, as an answer to the following telephone interview question: "I will read a list of health problems. Please stop me each time I name a health problem you have". Medications used to treat the cause of pain were not considered (eg, diseasemodifying antirheumatic drugs). Patients reported their use of nonprescription analgesics by answering the following question: "In the past 6 months, have you taken OTC medications or natural products for pain?" The number of prescribers (all specialists and primary-care physicians), and the number and types of analgesics dispensed were documented.

\section{Adverse effects associated with analgesics}

Adverse effects were documented using the following question in the self-administered questionnaire: "Because of your pain medication, how much were you bothered by the following gastrointestinal side effects - constipation, stomach aches and/or heartburn, nausea and/or vomiting?" Severity was rated using a six-point Likert scale ranging from 0 ("not experienced") to 5 ("extremely bothered"). ${ }^{13}$ Scores of 1-2 were considered as mild and scores of 3-5 as moderate to severe. The medications prescribed to prevent or treat gastrointestinal adverse effects were documented using the pharmacies' charts or RAMQ database; OTC medications were documented during the telephone interview through such questions as: "In the past 6 months, have you taken OTC medications or natural products for constipation?" with similar questions for heartburn and nausea/vomiting. Information on laxatives, acid suppressants and gastroprotectants, and antiemetic therapies were collected.

\section{Patients' satisfaction with pain treatment}

The Pain Treatment Satisfaction Scale (PTSS) ${ }^{13}$ was included in the self-administered questionnaire. Each item is scored on a five-point Likert scale ranging from 1-5. Each subscale score was calculated using the mean of items related to the same domain according to Evans et al. ${ }^{13}$ Scores were thereafter transformed into a 0-100 scale; higher scores indicated greater satisfaction. Overall patient satisfaction score was reported by computing the mean of the different domains scores. This questionnaire demonstrated internal consistency reliability coefficients ranging from $0.83-0.92 .{ }^{13}$ 
We used a forward-backward process to translate it into French. Cronbach coefficients for the French version were similar to the original version, ranging from $0.70-0.91 .^{34}$

\section{Data analyses}

For each psychosocial scale and satisfaction scale, overall and subscale scores were computed if patients answered more than $50 \%$ of items. To assess prevalence of use of each class of analgesic, patients who had at least one analgesic dispensed within the year preceding recruitment were considered as users. Patients who were dispensed at least one prescribed medication likely to treat a gastrointestinal adverse effect of analgesics and those reporting taking an OTC drug for management of gastrointestinal problems related to pain medication were considered as being treated for an adverse event.

To explore the determinants of patient satisfaction, multivariate linear regression models were developed. In each model, the overall PTSS satisfaction score and each PTSS subscale score was considered as the dependent variable.
Independent variables were patients' characteristics (including psychosocial characteristics), medical care (eg, number of analgesic prescribers, number of physicians visits), and pharmacotherapy. They were all included in a multivariate model. Thereafter, using a backward selection process, the final models were defined using a type 1 error of 0.05 as the threshold of statistical significance. Statistical analyses were performed with SPSS software, version 19.0 (IBM Corporation, Armonk, NY, USA) and SAS software, version 9.1 (SAS Institute Inc., Cary, NC, USA).

\section{Results}

Between May and October 2009, 296 community pharmacies were randomly selected to participate in the study; 70 of them (23.7\%) accepted and recruited patients (Figure 1). From May 2009 to January 2010, pharmacists referred 609 patients; 38 patients were ineligible and 85 patients refused to take part. On average, each pharmacy recruited seven patients (range, 1-17 patients). The telephone interview, the self-administered questionnaire, and the documentation
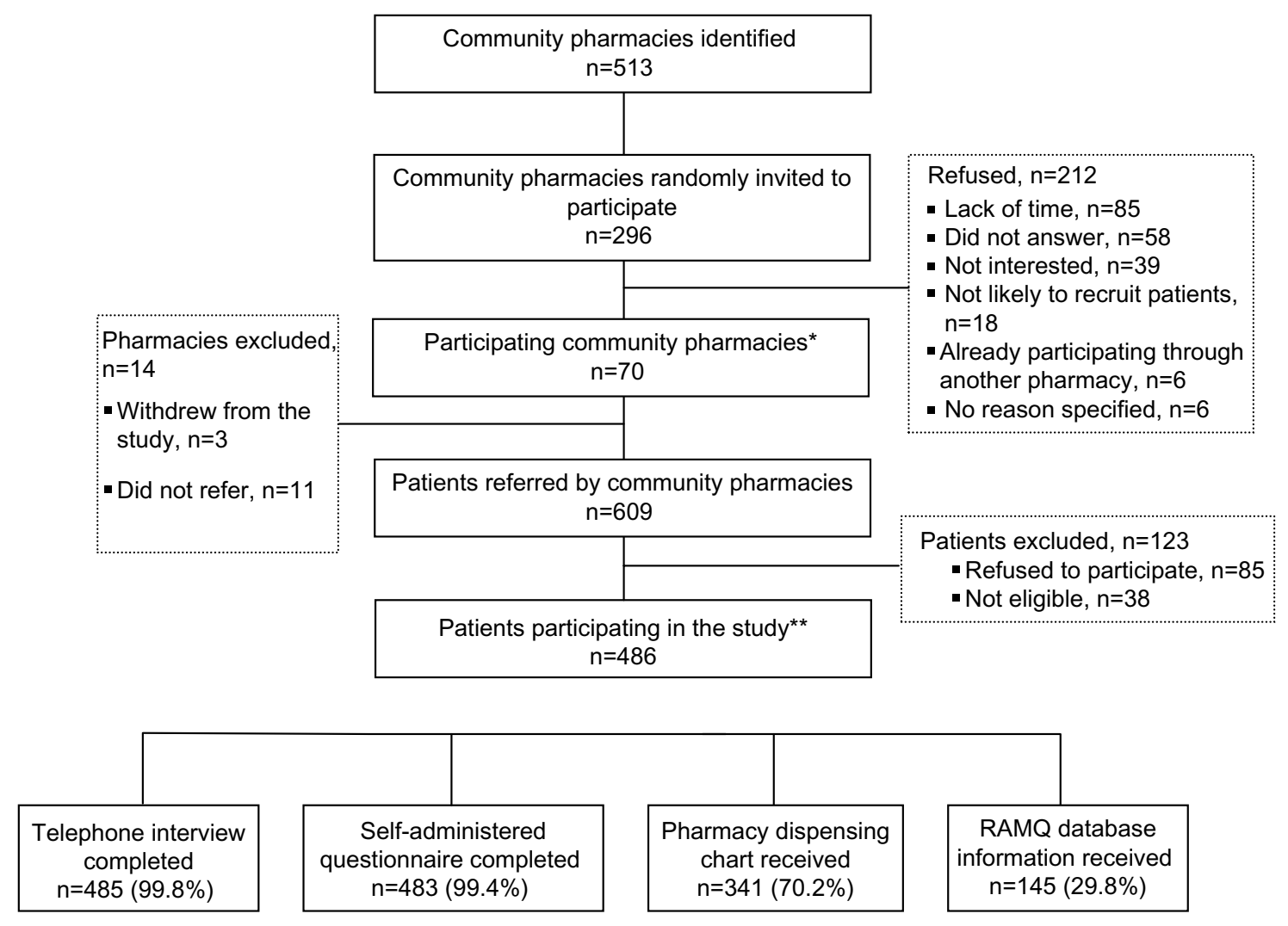

Figure I Recruitment of pharmacies and patients.

Notes: *Pharmacy distribution per region (number of recruited pharmacies/total number per region): Mauricie et Centre du Québec: $6 / 60$ (I0\%); Montréal: I8/I34 (I3.4\%); Laval: 13/70 (18.5\%); Lanaudière: 8/77 (13\%); Laurentides: I4/95 (14.7\%); Montérégie: I I/77 (14.3\%); **patients distribution per region (number of recruited patients per region/total number of patients): Mauricie et Centre du Québec: 44/486 (9\%); Montréal: 92/486 (I8.9\%); Laval: $67 / 486$ (I3.8\%); Lanaudière: 9 I/486 (I8.7\%); Laurentides: I I7/486 (24.1\%); Montérégie: 75/486 (15.4\%).

Abbreviations: n, number; RAMQ, Régie de l'assurance maladie du Québec. 
of prescribed analgesics were completed for 485,483 , and 486 patients, respectively.

\section{Patients' biopsychosocial characteristics}

As reported in Table 1, patients' mean age was 58.4 (standard deviation $[\mathrm{SD}]=12.5$ ) and women accounted for $67.7 \%$ of participants. About $54 \%$ were married or in a common-law relationship, and almost $70 \%$ were either unemployed, retired, or on temporary or permanent disability.

Patients reported a mean time since initial onset of pain of 11.7 years (Table 2). Nearly $75 \%$ of patients declared having suffered from continuous pain in the past 7 days. On a $0-10$ intensity scale, average pain intensity reported on the past 7 days was $6.5(\mathrm{SD}=1.9)$, and worst pain intensity was $8.1(\mathrm{SD}=1.8)$. The most frequently reported pain sites were legs, thighs, knees (64.6\%) and back (63.6\%). In fact, $82.1 \%$ of patients reported more than one pain site (not reported

Table I Demographic characteristics of patients

\begin{tabular}{|c|c|}
\hline Characteristics & $\mathrm{n}=486(\%)^{*}$ \\
\hline Age (years), mean (SD) & $58.4(12.5)$ \\
\hline 65-years-old and older & I 45 (29.8) \\
\hline Under 65 years old & $34 \mathrm{I}(70.2)$ \\
\hline Sex, women & $329(67.7)$ \\
\hline \multicolumn{2}{|l|}{ Mother tongue } \\
\hline French & 437 (89.9) \\
\hline English & $24(4.9)$ \\
\hline \multicolumn{2}{|l|}{ Highest level of education completed } \\
\hline None or elementary school & $132(27.2)$ \\
\hline Secondary school & $170(35.0)$ \\
\hline College technical school or university & $177(36.4)$ \\
\hline \multicolumn{2}{|l|}{ Civil status } \\
\hline Single & $64(13.2)$ \\
\hline Married or common-law relationship & $263(54.1)$ \\
\hline Separated or divorced & $98(20.2)$ \\
\hline Widowed & $57(11.7)$ \\
\hline \multicolumn{2}{|l|}{ Current work } \\
\hline Full-time job & $94(19.3)$ \\
\hline Part-time job & $27(5.6)$ \\
\hline Retired & I7I (35.2) \\
\hline Temporary or permanent disability & $100(20.6)$ \\
\hline Unemployed & $66(13.6)$ \\
\hline Other & $28(5.8)$ \\
\hline \multicolumn{2}{|c|}{ Annual family income before income tax deduction } \\
\hline$<\$ 20,000$ & $128(26.3)$ \\
\hline$\$ 20,000-\$ 50,000$ & $188(38.7)$ \\
\hline$>\$ 50,000$ & $117(24.1)$ \\
\hline \multicolumn{2}{|l|}{ Main source of income } \\
\hline Employment wages or salary & $155(31.9)$ \\
\hline Retirement pension & $15 \mid(31.1)$ \\
\hline Disability benefits & $86(17.7)$ \\
\hline Social assistance & $39(8.0)$ \\
\hline Personal savings or family member & $55(11.3)$ \\
\hline
\end{tabular}

Notes: *Unless otherwise indicated. Currency is Canadian dollars (CAD). Abbreviations: $\mathrm{n}$, number; $\mathrm{SD}$, standard deviation.
Table 2 Biopsychosocial characteristics of patients

\begin{tabular}{|c|c|}
\hline Characteristics & $n=486(\%) *$ \\
\hline Pain duration (years), ${ }^{* *}$ mean (SD) & $11.7(11.1)$ \\
\hline \multicolumn{2}{|l|}{ Frequency of pain in the past 7 days } \\
\hline Always & $363(74.7)$ \\
\hline Occasionally & $116(23.9)$ \\
\hline Never & $4(0.8)$ \\
\hline Average pain intensity in the past 7 days, ${ }^{\ddagger}$ mean (SD) & $6.5(1.9)$ \\
\hline Worst pain intensity in the past 7 days, ${ }^{* *}$ mean (SD) & $8.1(1.8)$ \\
\hline Current pain intensity, ${ }^{\ddagger}$ mean (SD) & $5.4(2.5)$ \\
\hline \multicolumn{2}{|l|}{ Sites of pain as reported by patients } \\
\hline Legs, thighs, knees & $3 \mid 4(64.6)$ \\
\hline Back & $309(63.6)$ \\
\hline Shoulders and/or arms & $252(51.9)$ \\
\hline Head and/or neck & $209(43.0)$ \\
\hline Chest and/or abdomen & $134(27.6)$ \\
\hline Hips & $114(23.5)$ \\
\hline \multicolumn{2}{|l|}{ Pain diagnoses as reported by patients ${ }^{\S}$} \\
\hline Osteoarthritis and other osteopathologies & $337(69.3)$ \\
\hline Chronic back pain & $292(60.1)$ \\
\hline Chronic neck pain & $185(38.1)$ \\
\hline Fibromyalgia & $114(23.5)$ \\
\hline Tendinitis, bursitis, capsulitis, epicondylitis & $98(20.2)$ \\
\hline Neuropathic pain" & $85(17.5)$ \\
\hline Pain related interference (BPI), mean (SD) & $5.3(2.2)$ \\
\hline Pain sleep impact (CPSI), mean (SD) & $5.1(2.9)$ \\
\hline \multicolumn{2}{|l|}{ Level of depression (HADS) } \\
\hline Absent & $254(52.3)$ \\
\hline Uncertain & 115 (23.7) \\
\hline Probable & $116(23.9)$ \\
\hline \multicolumn{2}{|l|}{ Level of anxiety (HADS) } \\
\hline Absent & $176(36.2)$ \\
\hline Uncertain & $115(23.7)$ \\
\hline Probable & $194(39.9)$ \\
\hline Barriers, prejudices and beliefs of patients & $2.6(0.7)$ \\
\hline \multicolumn{2}{|l|}{ (BQ-II), mean (SD) } \\
\hline Physiological effects, mean (SD) & $2.5(0.8)$ \\
\hline Fatalism, mean (SD) & $3.0(1.2)$ \\
\hline Communication, mean (SD) & $2.2(1.2)$ \\
\hline Harmful effects, mean (SD) & $3.1(1.3)$ \\
\hline $\begin{array}{l}\text { Pain Treatment Satisfaction Scale (PTSS), } \\
\text { mean }(95 \% \mathrm{Cl})\end{array}$ & $64.7(63.5-65.9)$ \\
\hline Satisfaction with current pain medication & $62.5(60.8-64.1)$ \\
\hline Medication characteristics subscale & $71.3(69.5-73.0)$ \\
\hline Efficacy subscale & $53.6(51.5-55.6)$ \\
\hline Medical care & $67.9(66.3-69.5)$ \\
\hline Impact of current pain medication & $58.0(55.9-60.0)$ \\
\hline Information about pain and its treatment & $50.6(47.6-53.7)$ \\
\hline Side effects of medication & $74.0(72.4-75.6)$ \\
\hline $\begin{array}{l}\text { Notes: *Unless otherwise indicated; **data missing for three } \\
\text { for four patients; Spatient may report more than one site of } \\
\text { includes diabetic neuropathies, postherpetic neuralgia, and tra } \\
\text { Abbreviations: BPI, modified Brief Pain Inventory; BQ-II, Bar } \\
\mathrm{Cl} \text {, confidence interval; CPSI, Chronic Pain Sleep Inventory; } \mathrm{H} \\
\text { and Depression Scale; n, number; PTSS, Pain Treatment } \\
\text { standard deviation. }\end{array}$ & $\begin{array}{l}\text { tients; } \text { ₹data missing } \\
\text { n; "neuropathic pain } \\
\text { natic neuropathies. } \\
\text { ers Questionnaire II } \\
\text { S, Hospital Anxiety } \\
\text { isfaction Scale; SD, }\end{array}$ \\
\hline
\end{tabular}

in table). Most common patient-reported diagnoses were osteoarthritis and other osteopathologies (69.3\%) and chronic back pain (60.1\%). About one in four patients $(23.5 \%)$ reported suffering from fibromyalgia, and $17.5 \%$ reported neuropathic pain. 
BPI (impact of pain on daily living) and sleep quality scores were around 5 on $0-10$ scales. Probable depression was identified in $23.9 \%$ of patients and anxiety in $39.9 \%$. The greatest patients' barriers to optimal pain treatment were fear of the potential harmful effects of analgesics $(3.1 ; \mathrm{SD}=1.3)$ and the perception that nothing can be done to treat $\mathrm{CNCP}$ better (3.0; $\mathrm{SD}=1.2])$.

The overall pain treatment satisfaction score was 64.7 (95\% CI $=63.5-65.9)$ on a $0-100$ scale. Subscale scores ranged from 50.6-74.0. Lowest scores were observed on the "information about pain and its treatment" subscale (50.6; $95 \% \mathrm{CI}=47.6-53.7)$ and the "efficacy" subscale $(53.6 ; 95 \%$ $\mathrm{CI}=51.5-55.6)$.

\section{Pain pharmacotherapy}

By design, all study patients had at least one analgesic prescribed by a primary-care physician dispensed in the year preceding recruitment (Table 3). About half (52.8\%) had analgesic prescriptions from two or more primarycare physicians and $39.7 \%$ had prescriptions from a pain specialist. In a year, on average, patients had prescribed analgesics dispensed on 22.4 different occasions ( $\mathrm{SD}=26.1$ ) with a median of 16 different occasions (not reported in table). Patients received a mean 4.2 different analgesics (range, 1-13 analgesics), and $23.3 \%$ received at least six different analgesics. The most prevalent classes of drugs used were nonsteroidal anti-inflammatory drugs $(72.0 \%$ of cohort patients), opioids (65.6\%), anticonvulsants (60.7\%), and antidepressants (49.8\%). Pregabalin was dispensed to $42.8 \%$ of patients (not reported in table). A total of $40.8 \%$ reported having used OTC medications and natural products in the previous 6 months. The most commonly used OTC product for pain relief was acetaminophen (used by $24.5 \%$ ). Overall, $45.9 \%$ of patients either had prescribed acetaminophen dispensed or reported using OTC medications (not reported in table).

The prevalence of gastrointestinal adverse effects attributed by patients to analgesics is reported in Table 3. The proportions of patients under treatment for the relief of these adverse effects were also documented (not reported in table). Among patients with constipation, the proportion of those who had prescribed laxatives dispensed was low (mild symptoms $=26.8 \%$; moderate to severe symptoms $=36.8 \%$ ) as was the proportion of patients who reported using OTC medications (mild symptoms $=27.5 \%$; moderate to severe $=40.6 \%$ ). A similar result was reported among patients having moderate to severe nausea and vomiting (prescribed antiemetic $=38.7 \%$, OTC medication $=19.4 \%$ ). Overall, $61.3 \%$
Table 3 Pharmacotherapy in the past year

$n=486(\%) *$

\begin{tabular}{|c|c|}
\hline \multicolumn{2}{|l|}{ Type of analgesic prescribers** } \\
\hline Primary-care physician & $486(100.0)$ \\
\hline Specialist & $193(39.7)$ \\
\hline Orthopedic surgeon & $35(7.2)$ \\
\hline Neurologist or neurosurgeon & $32(6.6)$ \\
\hline Psychiatrist & $29(6.0)$ \\
\hline Rheumatologist & $28(5.8)$ \\
\hline Specialist in physical medicine and rehabilitation & $20(4.1)$ \\
\hline Anaesthesiologist & $13(2.7)$ \\
\hline \multicolumn{2}{|l|}{$\begin{array}{l}\text { Number of primary-care physicians analgesics prescribers } \\
\text { per patient }\end{array}$} \\
\hline I primary-care physician & $229(47.1)$ \\
\hline 2 primary-care physicians & $146(30.0)$ \\
\hline 3 or more primary-care physicians & III (22.8) \\
\hline $\begin{array}{l}\text { Number of pharmacy visits to acquire analgesics, } \\
\text { mean (SD) }\end{array}$ & $22.4(26.1)$ \\
\hline Number of dispensed analgesics, mean (SD) & $4.2(2.2)$ \\
\hline I-2 analgesics & $118(24.3)$ \\
\hline $3-5$ analgesics & $255(52.5)$ \\
\hline 6 or more analgesics & $113(23.3)$ \\
\hline \multicolumn{2}{|l|}{ Prevalence by class of analgesic dispensed $* *$} \\
\hline Nonsteroidal anti-inflammatory drugs & $350(72.0)$ \\
\hline Opioids & $319(65.6)$ \\
\hline Anticonvulsants & $295(60.7)$ \\
\hline Antidepressants & $242(49.8)$ \\
\hline Acetaminophen & $138(28.4)$ \\
\hline Muscle relaxants & $126(25.9)$ \\
\hline Prevalence of use of OTC analgesics ${ }^{\ddagger \S}$ & $197(40.8)$ \\
\hline \multicolumn{2}{|l|}{ Prevalence of most often used OTC analgesics ${ }^{\ddagger}$} \\
\hline Acetaminophen & $119(24.5)$ \\
\hline Ibuprofen & $43(8.8)$ \\
\hline Glucosamine & $32(6.6)$ \\
\hline Collagen & $17(3.5)$ \\
\hline \multicolumn{2}{|l|}{ Prevalence of constipation } \\
\hline Not experienced & $124(25.5)$ \\
\hline Mild & $138(28.4)$ \\
\hline Moderate to severe & $220(45.3)$ \\
\hline \multicolumn{2}{|l|}{ Prevalence of nausea and vomiting } \\
\hline Not experienced & $219(45.1)$ \\
\hline Mild & $170(35.0)$ \\
\hline Moderate to severe & $93(19.1)$ \\
\hline \multicolumn{2}{|l|}{ Prevalence of heartburn and stomach aches } \\
\hline Not experienced & $165(34.0)$ \\
\hline Mild & $156(32.1)$ \\
\hline Moderate to severe & $164(33.7)$ \\
\hline
\end{tabular}

Notes: *Unless otherwise indicated; **more than one answer possible; ${ }^{*}$ prevalence for past 6 months; §data missing for three patients.

Abbreviations: $\mathrm{n}$, number; OTC, over-the-counter; SD, standard deviation.

of these patients were not taking prescribed antiemetics. Prescribed acid suppressants and gastroprotectants were commonly dispensed to patients reporting heartburn and stomach aches ( mild symptoms $=52.6 \%$; moderate to severe $=71.3 \%$ ). However, $18.9 \%$ of patients reporting moderate to severe stomach aches/heartburn did not use either prescribed or OTC medications to relieve their symptoms. Overall, although $90 \%$ reported adverse gastrointestinal effects, $36.4 \%$ and 
$54.4 \%$ of these patients took no OTC or prescribed medication for constipation or nausea, respectively.

\section{Determinants of patients' satisfaction with pain treatment}

As reported in Table 4, in a multivariate model, the overall treatment satisfaction (overall PTSS score) was lower among patients reporting more pain disability $(-1.2$ for each additional point on the BPI scale), those with probable depression ( -4.4 points when compared to those with possible or no depression) and probable anxiety ( -4.4 points), as well as those reporting more barriers to pain treatment ( -4.3 points). Use of OTC and suffering from moderate to severe nausea were also negatively correlated with overall treatment satisfaction. Together, they accounted for 33\% of the overall treatment satisfaction variance. Characteristics not listed in Table 4 were not statistically significant predictors of the overall score or any of the subscale scores. These included pain characteristics (intensity, frequency, number of sites), medical care characteristics (number of primary-care physicians prescribing analgesics, care by a pain specialist), and other pharmacotherapy characteristics (being an opioid user, opioid dosage, suffering from moderate to severe constipation or heartburn). Characteristics that influenced several treatment satisfaction subscales included pain disability as measured by the BPI, barriers to pain treatment, use of OTC analgesics, and suffering from moderate to severe nausea.

\section{Discussion}

This unique cohort study provides a comprehensive assessment of 486 primary-care patients suffering from uncontrolled CNCP. These patients had pain for more than a decade with significant disability and a high prevalence of probable depression and anxiety. On average, they were unconvinced that chronic pain can be adequately relieved and had concerns about the potential harmful addictive effects of analgesics. Prevalence of adverse gastrointestinal effects was high and, for the most part, left untreated by prescription or OTC drugs. Unsurprisingly, patients' satisfaction with pain treatment was negatively correlated with high pain disability, barriers about pain treatment, depression, anxiety, use of OTC pain relievers, and suffering from moderate to severe nausea. All primary-care clinicians involved in the management of $\mathrm{CNCP}$ should be concerned by these results. However, considering the frequency at which community pharmacists saw these patients (mean of 22.4 visits per year) as well as the expansion of their scope of practice, from a pharmacist's point of view, several lessons may be drawn from this survey.
To evaluate the effectiveness of a pain treatment, monitoring pain relief is not enough; treatment satisfaction is more closely associated with pain disability. Others have also reported a weak relationship between pain severity and patient satisfaction. ${ }^{17,18}$ For most patients with CNCP, aiming at a complete cure is often not an option. ${ }^{35}$ However, attenuating the impact of pain on daily life is possible and important for patients. ${ }^{36}$ Patients are usually dissatisfied by their treatment when their expectations are not met, ${ }^{37,38}$ which highlights the importance of establishing realistic and achievable goals. ${ }^{38}$ In this regard, our results suggest that pain disability needs to be considered when defining treatment objectives. Pharmacists may help patients in setting their own treatment objectives and adjusting their pharmacotherapy appropriately by monitoring their pain disability. This could be done using the BPI. ${ }^{25}$

Emotional wellbeing was also associated with patient satisfaction. Others have reported similar associations, ${ }^{12,18,39}$ and several studies suggest that psychological interventions can improve pain and disability. ${ }^{20,21,40}$ Kroenke et a ${ }^{21}$ showed that optimized antidepressant therapy coupled with a pain self-management program in primary-care patients with chronic musculoskeletal pain and comorbid depression resulted in moderate reductions in both pain severity and pain-related disability. Pharmacists should not hesitate to refer patients to their physicians and psychologists for appropriate treatment when needed. They may also play a pivotal role in optimizing antidepressant treatment by improving adherence to and persistence with treatment.

Patients with CNCP need to be better informed and educated regarding chronic pain and its management, the area where patients were most dissatisfied with their pain treatment. Furthermore, patients' concerns about the potential harmful addictive effects of analgesics use may compromise the effectiveness of their treatment. ${ }^{41}$ Misconceptions and misunderstandings about pain therapeutics play an important role in the suboptimal management of pain..$^{42}$ Patient perceptions of the completeness and appropriateness of treatment can enhance motivation and compliance with treatment and may be a strong predictor of treatment and care satisfaction. ${ }^{12,43}$ According to Main et $a 1,{ }^{43}$ patient beliefs are "a core part of pain perception" and influence response to treatment. Pharmacists can provide information about treatment and discuss barriers, beliefs, and attitudes about pain and its treatment. A few studies have evaluated the impact of pharmacists' educational interventions towards patients with chronic pain and shown positive results on the incidence of adverse events and improvement in patient satisfaction. ${ }^{44}$ 


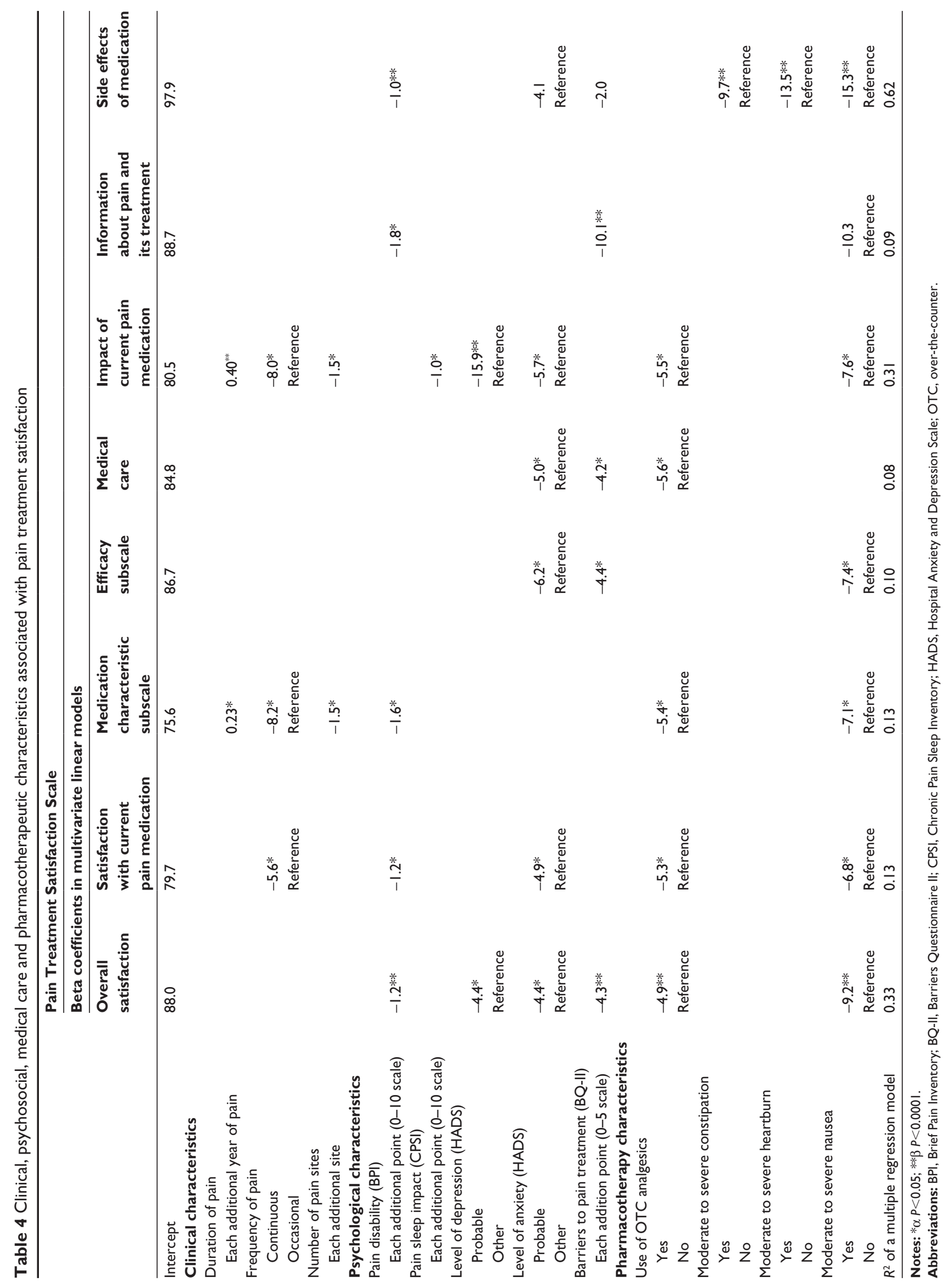


However, the impact of pharmacists' interventions on patients' barriers, beliefs, and attitudes about pain treatment remains to be evaluated.

The adverse effects of analgesics may limit effectiveness of treatment and decrease treatment satisfaction. ${ }^{41}$ In our study, the prevalence of adverse gastrointestinal effects attributed to analgesics was high and was often left untreated by either prescription or OTC drugs. Similarly, Williams et $\mathrm{a}^{22}$ showed that only $30 \%$ of Quebecers who were dispensed an opioid in 2005 were also dispensed medications to prevent gastrointestinal adverse effects. In the Netherlands, a study showed that only $37 \%$ of patients receiving a first prescription for a strong opioid also began to take a laxative within 5 days of starting therapy. ${ }^{45}$ The exploratory trial by Bruhn et $\mathrm{al}^{46}$ suggests that pharmacist medication review with or without face-to-face pharmacist prescribing may be beneficial for patients with chronic pain in terms of pain intensity and mental well-being. In Quebec, collective prescriptions could easily be implemented to allow pharmacists to appropriately prevent or relieve gastrointestinal adverse effects of analgesics treatment. Collective prescriptions are written and approved by a group of clinicians, including physicians and health authorities. They allow nurses and/or pharmacists to perform clinical tasks that normally fall outside their scope of practice (eg, prescribing medication). ${ }^{47}$ Collective prescriptions are essential to allow pharmacists to play a more active role to ensure the effectiveness of, safety of, and adherence to analgesic treatment.

\section{Strengths and limitations}

The study was designed to increase external validity: recruitment in pharmacies facilitated the inclusion of patients followed by a relatively high number of primary-care physicians, a formal sampling frame of pharmacies was defined, and the random selection of pharmacies was stratified and weighted by region. On the other hand, pharmacy participation rate was low $(23.6 \%)$. We had no information about patients who decided not to fill their analgesic prescription and patients taking only OTC analgesics. Our conclusions can only be generalized to $\mathrm{CNCP}$ patients receiving active treatment from a primary-care physician.

The internal validity of our results is high considering that the response rates for the self-administered and telephone questionnaires were very high and we were able to document the pharmacotherapy of all patients using two reliable sources of information. However, it is important to emphasize that all pain diagnoses, analgesic side effects, and OTC medication use were self-reported by patients.
Moreover, pharmacotherapy was described using dispensed drugs; we have no information regarding their actual intake by patients. Also, we do not know what the indication for each prescription was. Although we only documented antidepressants and neuroleptics use among patients not reporting depression or epilepsy, respectively, we may have overestimated their prevalence of use as pain relievers.

\section{Conclusion}

This study underlines how the expanded scope of practice of community pharmacists may allow them to play a pivotal role in the pharmacotherapeutic management of these patients by providing information, discussing barriers, beliefs, and attitudes about pain and its treatment, and monitoring pain disability, and by appropriately managing pharmacotherapy to optimize effectiveness while minimizing adverse effects.

\section{Acknowledgments}

We are grateful for the motivation of the community pharmacists and patients who took part in this project. Our thanks to Chantal Legris for the preparation and submission of this article. Lyne Lalonde and Sylvie Perreault are scientists supported by the Fonds de recherche du Québec - Santé.

\section{Disclosure}

This study was funded by a team grant - Community Alliances for Health Research and Knowledge Translation on Pain of the Canadian Institutes of Health Research (CIHR) in partnership with AstraZeneca Canada Inc. (Grant \# 86787), and by Pfizer Canada Inc. The authors report no other conflicts of interest in this work.

\section{References}

1. Moulin DE, Clark AJ, Speechley M, Morley-Forster PK. Chronic pain in Canada - prevalence, treatment, impact and the role of opioid analgesia. Pain Res Manag. 2002;7(4):179-184.

2. Boulanger A, Clark AJ, Squire P, Cui E, Horbay GL. Chronic pain in Canada: have we improved our management of chronic noncancer pain? Pain Res Manag. 2007;12(1):39-47.

3. Breivik H, Collett B, Ventafridda V, Cohen R, Gallacher D. Survey of chronic pain in Europe: prevalence, impact on daily life, and treatment. Eur J Pain. 2006;10(4):287-333.

4. Blyth FM, March LM, Brnabic AJ, Jorm LR, Williamson M, Cousins MJ. Chronic pain in Australia: a prevalence study. Pain. 2001;89(2-3): $127-134$.

5. Gureje O, Von Korff M, Simon GE, Gater R. Persistent pain and wellbeing: a World Health Organization Study in Primary Care. JAMA. 1998;280(2):147-151.

6. Turk DC. Chronic non-malignant pain patients and health economic consequences. Eur J Pain. 2002;6(5):353-355.

7. Thomsen AB, Sørensen J, Sjøgren P, Eriksen J. Chronic non-malignant pain patients and health economic consequences. Eur J Pain. 2002;6(5): $341-352$. 
8. Lynch ME, Watson CP. The pharmacotherapy of chronic pain: a review. Pain Res Manag. 2006;11(1):11-38.

9. Nguyen M, Ugarte C, Fuller I, Haas G, Portenoy RK. Access to care for chronic pain: racial and ethnic differences. J Pain. 2005;6(5): 301-314.

10. Rovine T, Ferrero CL. Chronic Pain in America: Roadblocks to Relief. Chicago, IL: American Pain Society; 1999. Available from: http://www. doctordeluca.com/Library/Pain/ChronicPainRoadblocks.htm. Accessed February 3, 2014.

11. Schappert SM, Burt CW. Ambulatory care visits to physician offices, hospital outpatient departments, and emergency departments: United States, 2001-2002. Vital Health Stat 13. 2006;(159):1-66.

12. Hirsh AT, Atchison JW, Berger JJ, et al. Patient satisfaction with treatment for chronic pain: predictors and relationship to compliance. Clin J Pain. 2005;21(4):302-310.

13. Evans CJ, Trudeau E, Mertzanis P, et al. Development and validation of the Pain Treatment Satisfaction Scale (PTSS): a patient satisfaction questionnaire for use in patients with chronic or acute pain. Pain. 2004;112(3):254-266.

14. Trescot AM, Helm S, Hansen H, et al. Opioids in the management of chronic non-cancer pain: an update of American Society of the Interventional Pain Physicians' (ASIPP) Guidelines. Pain Physician. 2008;11(Suppl 2):S5-S62.

15. Noble M, Treadwell JR, Tregear SJ, et al. Long-term opioid management for chronic noncancer pain. Cochrane Database Syst Rev. 2010;1:CD006605.

16. McDermott AM, Toelle TR, Rowbotham DJ, Schaefer CP, Dukes EM. The burden of neuropathic pain: results from a cross-sectional survey. Eur J Pain. 2006;10(2):127-135.

17. Dawson R, Spross JA, Jablonski ES, Hoyer DR, Sellers DE, Solomon MZ. Probing the paradox of patients' satisfaction with inadequate pain management. J Pain Symptom Manage. 2002;23(3):211-220.

18. Bair MJ, Kroenke K, Sutherland JM, McCoy KD, Harris H, McHorney CA. Effects of depression and pain severity on satisfaction in medical outpatients: analysis of the Medical Outcomes Study. J Rehabil Res Dev. 2007;44(2):143-152.

19. Meredith LS, Orlando M, Humphrey N, Camp P, Sherbourne CD. Are better ratings of the patient-provider relationship associated with higher quality care for depression? Med Care. 2001;39(4):349-360.

20. Lin EH, Katon W, Von Korff M, et al. Effect of improving depression care on pain and functional outcomes among older adults with arthritis: a randomized controlled trial. JAMA. 2003;290(18):2428-2429.

21. Kroenke K, Bair MJ, Damush TM, et al. Optimized antidepressant therapy and pain self-management in primary care patients with depression and musculoskeletal pain: a randomized controlled trial. JAMA. 2009;301(20):2099-2110.

22. Williams RE, Bosnic N, Sweeney CT, et al. Prevalence of opioid dispensings and concurrent gastrointestinal medications in Quebec. Pain Res Manag. 2008;13(5):395-400.

23. Williams RE, Bosnic N, Duncan AW, Brogan M, Cook SF. Prevalence of opioid dispensings and concurrent gastrointestinal medications in an elderly population from Ontario, Canada. $J$ Opioid Manag. 2008;4(4):193-200.

24. Lalonde L. Formation et intervention en soins de première ligne: Optimisation de la gestion de la douleur chronique en soins ambulatoires de première ligne. [Education and intervention in primary care. Optimizing the management of chronic pain in ambulatory primary care]. [homepage on the Internet]. Available from: http://www.programmeaccord.org/ volets/premiereligne. Accessed April 22, 2013. French.

25. Cleeland CS, Ryan KM. Pain assessment: global use of the Brief Pain Inventory. Ann Acad Med Singapore. 1994;23(2):129-138.

26. Tyler EJ, Jensen MP, Engel JM, Schwartz L. The reliability and validity of pain interference measures in persons with cerebral palsy. Arch Phys Med Rehabil. 2002;83(2):236-239.

27. Kosinski M, Janagap CC, Gajria K, Schein J. Psychometric testing and validation of the Chronic Pain Sleep Inventory. Clin Ther. 2007; 29 Suppl:2562-2577.
28. Zigmond AS, Snaith RP. The hospital anxiety and depression scale. Acta Psychiatr Scand. 1983;67(6):361-370.

29. Bjelland I, Dahl AA, Haug TT, Neckelmann D. The validity of the Hospital Anxiety and Depression Scale. An updated literature review. J Psychosom Res. 2002;52(2):69-77.

30. Castro MM, Quarantini L, Batista-Neves S, Kraychete DC, Daltro C, Miranda-Scippa A. [Validity of the hospital anxiety and depression scale in patients with chronic pain]. Rev Bras Anestesiol. 2006;56(5): 470-477. Portuguese.

31. Gunnarsdottir S, Donovan HS, Serlin RC, Voge C, Ward S. Patientrelated barriers to pain management: the Barriers Questionnaire II (BQ-II). Pain. 2002;99(3):385-396.

32. Moulin DE, Clark AJ, Gilron I, et al; Canadian Pain Society. Pharmacological management of chronic neuropathic pain - consensus statement and guidelines from the Canadian Pain Society. Pain Res Manag. 2007;12(1):13-21.

33. O'Connor AB, Dworkin RH. Treatment of neuropathic pain: an overview of recent guidelines. Am J Med. 2009;122(Supp1 10): $\mathrm{S} 22-\mathrm{S} 32$

34. Jouini G, Choinière M, Dion D, et al. Programme ACCORD: validation of a French version of the pain treatment satisfaction scale in primary care patients with non-cancer chronic pain [abstract]. Annual conference of the Canadian Association for Population Therapeutics; March 28-30, 2010; Toronto, Canada. Can J Clin Pharmacol. 2010;17(1):e117;58.

35. van Huet H, Innes E, Stancliffe R. Occupational therapists perspectives of factors influencing chronic pain management. Aust Occup Ther J. 2013;60(1):56-65.

36. Bromley Milton M, Börsbo B, Rovner G, Lundgren-Nilsson A, Stibrant-Sunnerhagen K, Gerdle B. Is pain intensity really that important to assess in chronic pain patients? A study based on the Swedish Quality Registry for Pain Rehabilitation (SQRP). PLoS One. 2013;8(6): e65483.

37. Verbeek J, Sengers MJ, Riemens L, Haafkens J. Patient expectations of treatment for back pain: a systematic review of qualitative and quantitative studies. Spine (Phila Pa 1976). 2004;29(20): 2309-2318.

38. Liddle SD, Baxter GD, Gracey JH. Chronic low back pain: patients' experiences, opinions and expectations for clinical management. Disabil Rehabil. 2007;29(24):1899-1909.

39. Linn LS, Brook RH, Clark VA, Davies AR, Fink A, Kosecoff J. Physician and patient satisfaction as factors related to the organization of internal medicine group practices. Med Care. 1985;23(10):1171-1178.

40. Ang DC, Bair MJ, Damush TM, Wu J, Tu W, Kroenke K. Predictors of pain outcomes in patients with chronic musculoskeletal pain co-morbid with depression: results from a randomized controlled trial. Pain Med. 2010;11(4):482-491.

41. Gregorian RS, Gasik A, Kwong WJ, Voeller S, Kavanagh S. Importance of side effects in opioid treatment: a trade-off analysis with patients and physicians. J Pain. 2010;11(11):1095-1108.

42. Fitzcharles MA, DaCosta D, Ware MA, Shir Y. Patient barriers to pain management may contribute to poor pain control in rheumatoid arthritis. J Pain. 2009;10(3):300-305.

43. Main CJ, Foster N, Buchbinder R. How important are back pain beliefs and expectations for satisfactory recovery from back pain? Best Pract Res Clin Rheumatol. 2010;24(2):205-217.

44. Bennett MI, Bagnall AM, Raine G, et al. Educational interventions by pharmacists to patients with chronic pain: systematic review and meta-analysis. Clin J Pain. 2011;27(7):623-630.

45. Bouvy ML, Buurma H, Egberts TC. Laxative prescribing in relation to opioid use and the influence of pharmacy-based intervention. J Clin Pharm Ther. 2002;27(2):107-110.

46. Bruhn H, Bond CM, Elliott AM, et al. Pharmacist-led management of chronic pain in primary care: results from a randomised controlled exploratory trial. BMJ Open. 2013;3(4):e002361.

47. Desrosiers G. Bill 90: repercussions for all nurses. Perspect Infirm. 2007;4(3):8-10, 6-8. 
Journal of Pain Research

\section{Publish your work in this journal}

The Journal of Pain Research is an international, peer-reviewed, open access, online journal that welcomes laboratory and clinical findings in the fields of pain research and the prevention and managemen of pain. Original research, reviews, symposium reports, hypothesis formation and commentaries are all considered for publication.
Dovepress

The manuscript management system is completely online and includes a very quick and fair peer-review system, which is all easy to use. Visit http://www.dovepress.com/testimonials.php to read real quotes from published authors.

\footnotetext{
Submit your manuscript here: http://www.dovepress.com/journal-of-pain-research-journal
} 